\title{
Evolutional Epistemology and Evolutional Constructivism as Cognitive Practices of the Modern Science
}

\author{
Irina V. Chernikova ${ }^{1}$, Darya V. Chernikova ${ }^{2 \text { a }}$ \\ ${ }^{1}$ National Research Tomsk State University, National Research Tomsk Polytechnic University, Russia \\ ${ }^{2}$ National Research Tomsk Polytechnic University, Russia
}

\begin{abstract}
In the paper the cognitive apparatus of the modern science is observed. An approach to cognition of complex, self-developing systems as an object of the modern science resulted in necessity of reasoning of their cognition specifics. The authors focus on the following questions: how historical, temporal and sociocultural parameters may be inserted to the epistemology; how the category of truth and objectivity of scientific knowledge may be rethought in light of understanding cognition as interpretative activity with the insertion of constructivist ideas? It is highlighted that evolutional constructivism and evolutional epistemology are the most adequate epistemological practices for cognition of complex, self-developing systems, explanation of the existence and evolutional processes.
\end{abstract}

\section{Introduction}

In the epistemological schemes, fundamental for the modern scientific cognition, the model of cognition as construction is mostly spread. Contemporary natural science turned from the subject oriented cognition to the cognition of reality, understood as interconnection, relation; from the thingish reality, visually observed - to the reality of process-systems, reality mentally constructed. That sort of cognitive practice can be accomplished by reflection able to challenge the understanding of ambiguity, complexity, integrity. The cognitive relationships in the contemporary postnonclassical science are defined by the openness of the cognitive space, in which the self-developing systems are examined by the evolving actor. The cognitive situation itself is characterized by the scientists (Humberto Maturana, Francisco Varela, Erich Janch) like an autopoetical process. The language of philosophy describes such cognitive act as the construction of existence by conscience. It is not sufficient to interpret the cognition like intellectual production. The essence of the cognition is that the object is constructed in the intellectual and cultural space of the humane activity. Herewith the subjective part of the cognition does not contravene the objective one.

The modern philosophy of science sees in science not only the system of theoretical statements, but the interpretative practice rooted in the live world as well. An appeal to the cognition of complex self-developing systems, including a human being, so called "humanedimension", implies the change of epistemology.
Logicism as a scientific method is opposed to the imagination and creativity. The adequate theoretical understanding of such a reality is an integral part of mental and communicative processes. We are learning to see the world not only through the instruments, but through the human being as well. The recourse to the perception of the complex self-organising systems, which became the object of science in the second half of the XX century, resulted again in the necessity of understanding of peculiarities of cognition nowadays [1]. The question is how to insert historical, temporal and socio-cultural parameters to epistemology? How to rethink the category of truth and objectivity of the scientific knowledge in the context of the understanding of cognition like the interpretative activity, with the implementation of constructivist ideas?

The necessity appears to explain the links between the fundamental intra-scientific values and extrascientific values of a social character. In the second half of the XX century in philosophy of science the revision of the traditional concepts of rationality as a whole and correlation between theory and practice was made. From the position of the traditional philosophy of science the technology was considered a continuation and supplement of science. Nowadays in matters of cognition, western philosophy offers two main approaches. One of them is signified as a fundamental approach claiming that cognition of the reality is independent from the conscience. The second, is called the concept of the historical design, which is contained in the idea that we do not know and we are not able to know the reality independent from the conscience, but

\footnotetext{
${ }^{\text {a }}$ Corresponding author: $\underline{\operatorname{chdv} @ \text { tpu.ru }}$
} 
we only know the empirical reality, which we design (in some sense) as a result of interaction with the incognoscible outer world.

\section{Research methodology}

In the middle of the XX century the trend, called evolutional epistemology, appeared in English-speaking countries (Karl Popper, Stiven Toulmin, Joseph Campbell), and evolutional theory of cognition - in German-speaking countries (Konrad Lorenz, Gerhard Follmer, Matt Ridley). Evolutional epistemology is defined like "cognition theory which interprets human as a product of biological and social evolution" [2]. The subject of evolutional epistemology is an evolution of cognitive structures, mechanisms of the knowledge growth and cognition as function of development and life. Thus, evolutional epistemology appears simultaneously as "biologisation of epistemology" and "epistemologisation of biology", new interdisciplinary communication of science and philosophy.

This trend received the substantial impetus for further development in the later works of Humberto Maturana and Francisco Varela. Ideologically close to the evolutional epistemology is the genetic epistemology of Jean Piaget and naturalized epistemology of Willard Quine. At the early stages of its development the genetic epistemology and evolutional epistemology were considered as complementary approaches: evolutional epistemology describes the cognition in phylogenesis, and genetic epistemology in ontogeny. Hereafter, as Joseph Campbell states, evolutional epistemology, in the basis of which is the postulate of the universal evolution, started to embrace the Piaget's theory.

The evolving new trend was connected with the orientation to the research of the real cognitive process with the means of the evolutional natural science, first of all biology. The target of the evolutional epistemology is research of the biological suppositions of the cognition and the explanation of its peculiarities on the basis of the modern evolutional opinions. The evolutional epistemology, as opposed to the classical epistemology aspiring (notionally) to create the ideal model of the cognition, turned to the research of the real cognition processes.

One of the founders of this trend is considered to be the Austrian biologist, Konrad Lorenz, the 1973 Nobel laureate in medicine and physiology. His works "Kant's Doctrine about Aprioristic in light of the Modern Biology" and "The Reverse Side of the Mirror" acquired fundamental value for the evolutional theory. The initial point of the research is the statement of Immanuel Kant on aprioristic forms of mind. In accordance with the apriorism the mind is not "une carte blanche", the man comes to a phenomenon with the definite forms of meditation and thinking, with the help of which he sorts the phenomena. Where the aprioristic forms come from? The evolutional cognition theory is approaching this gnoseological problem. "A priori is based on the central nervous system, which is as real as the objects of the external world, which phenomenal form it (a priori) sets for us" [3]. In accordance with the Lorenz's opinion, while interpreting cognition as natural historical process we inscribe cognitive experience in the evolutional process. Thereat, the cognitive structures aprioristic for individual turn to be posterior for species. The essence of the evolutional epistemology he expressed as follows: our cognitive abilities are the attainment of inborn apparatus of the world reflection, which was developed in frames of the generic humane history and gives the opportunity of the factual approach to the non-subjective reality.

The evolutional epistemology represents the epistemological system where the cognition is understood like a whole physiologically-mental process. The evolutional epistemology gives the answer to the problem proposed by Immanuel Kant - regarding the origin of the aprioristic forms of cognition. According to the evolutional epistemology the mind in the process of the knowledge attainment follows the definite predetermined pattern of thinking. The idea, as the supporters of the evolutional epistemology note, is that the isomorphism of forms exists between the conceptual net of science and the conceptual order of mind, so the conceptual development of science goes parallel with the conceptual development of mind. Herewith the mind does not stay passive and it does not disengage the ontological basis, it interacts with the net and transforms it. The ontological context in the evolutional epistemology is not just obvious, it gives sense to it, and it is not only specific feature, but the advantage of evolutional epistemology as a cognitive practice.

\section{Discussion}

Every cognition theory is based on the system of ontological ideas. When science approached studying complex self-developing systems, it resulted in new scientific rationality, specified by the outstanding Russian philosopher, V.S. Styopin, as a postnonclassical paradigm of science [4]. This paper is focused on the cognitive practices adequate for cognition of complex self-developing systems. First of all, let's reflect on the evolutional epistemology application in the postnonclassical science. As Jean Piaget noted, the science historically forms the epistemology and is the source of its new problems. For example, to explain the apriority he used not only the evolutional biology, but the synergetics as well (right after its appearance). In the scientific-analytical review "Jean Piaget's Cognition Theory and Evolutional Epistemology" the contact points between Jean Piaget's and Joseph Prigozhin's ideas were found [5]. We will try to show the adequacy of the evolutional epistemology to the cognitive content of the postnonclassical science.

Likewise, it is worth paying attention to the correlation between the main postulates (realism, structural properties, interaction and objectivity) of the evolutional epistemology and the worldview, which is the basis of the postnonclassical science. The fundamental idea of the scientific worldview, not only in the postnonclassical science, but as well in science in 
general, is the scientific realism. May we remind, that the objects of the postnonclassical science are complex self-organising systems. The hierarchy of the elements' level organisation is incidental to the self-organising systems; at that, each new level pays the reverse influence. Moreover, for both, the evolutional epistemology and the postnonclassical science the idea of the global evolutionism has the fundamental meaning.

Characterising the worldview formed by the postnonclassical science, the researchers highlight the crucial meaning of the global evolutionism idea, including the connection of the evolutional and system notions [4]. In the authors' works it was mentioned as well, that "the idea of the global evolution is connected to, firstly, representation of the evolvement, innovation and variability; and secondly, representation of the consistency, integrity and interdependence". We acknowledge it with the fragment of the earlier publications. "On the basis of the global evolutionism idea the picture of the world appears as the selfdeveloping supersystem, every object appears as its integral part: as an event and as a system simultaneously. Every object here is considered in a systemic quality, and the cognition is not opposed to process. Processuality becomes the universal characteristic. However, the other thing is important as well. Let us take into consideration the integrity of the Universum, where all the parts are systems themselves (cosmic space is a system of the galaxies, stars, planets; geosphere is a system of the geological objects; biosphere is a system of a living substance; systems of the particles interaction, information systems and etc.), are interconnected and at the same time keep the integrity. Calling any system the holistic one, we should always keep in mind the environment, where it can be developed and consider that the environment can develop as well. The environment potentially contains different types of the process localization. The environment is a certain single origin, acting as a platform with the various forms of the future organisation, as a field of the ambiguous ways of development. Thus, any evolution appears like coevolution of the system and its environment" [6].

Summing up, we shell emphasize that the main features appropriate for the evolutional epistemology, evolutionism, realism, tendency to impart the universal meaning to evolution are common for the postnonclassical science as well. It speaks in favor of the general ontological roots of the evolutional epistemology and the postnonclassical science. Let us give the additional arguments for the abovementioned. The theoretical carcass of the postnonclassical science is formed by synergetics. The basic principles of synergetics are the principles of existence and formation. To the principles of existence we can assign the principles of the homeostaticity and of the hierarchical pattern. To the principles of formation - nonlinearity, instability, openness, dynamic hierarchical pattern and observance. Two last principles include the principle of complementarity and conformity, circular communicativeness and relativity to the means of observation, launching the dialogue between the internal observer and metaobserver [7].
Cognition in the evolutional epistemology is also characterized by the cyclicity. As Humberto Maturana and Francisco Varela notice the evolutional approach to the cognition provokes "giddiness". In their concept of autopoesis the synergetic approach is applied to the study of the cognitive process. The image of the Humberto Maturana and Francisco Varela autopoesis ontology is reflected in the etchings of Maurits Cornelis Escher "Drawing Hands" and "Picture Gallery"; their work "The Tree of Knowledge: The Biological Roots of Human Understanding" was illustrated by these etchings. Their research influenced significantly the notions of the nature of cognition, and it became the new scientific argument in favour of the evolutional epistemology. Aiming at the cognition of cognition "without any autonomous reference system" the authors confirmed one of the main theses of the evolutional epistemology: the life, in the aspect of its constitutive essence, is a cognitive process, and the cognition is a construction of the new structural links and correlations [8]. The cognition is given as an adaptive mechanism, as an element of the evolutional dynamics, as a function of life and as a constitutive process. The research of Humberto Maturana and Francisco Varela is not only the important step towards the development of the theoretical carcass of the evolutional epistemology, the concept of the autopoesis, created by them, is conformable to synergetics. They study the cognition process "not only as representation of the world "cutand-dried", but as continuous creation of the world through the process of life itself" [8], that is on the basis of the self-organisation principle, as a self-organising system. The authors displayed the properties of the autopoetical systems ("openness", "operative closeness", spontaneity...) and formulated the principles of interaction ("relation", "structural coupling", "natural drift"...).

The evolutional-synergetic approach to cognition enabled the authors to build the model where the cognition goes like a communicative activity. Taking into consideration that synergetics is the centre of the postnonclassical science we can state that the research of Humberto Maturana and Francisco Varela, combining the principles of the evolutional epistemology and synergetics, displays the functional matching of the evolutional epistemology and postnonclassical science. The matching of the evolutional epistemology and postnonclassical science appears as well in the similar understanding of cognition and knowledge growth. Knowledge growth comes out not only like the increase of reality copies quantity and not like expanding of inborn ideas in the logical constructions, but like a continuous process of structuring of information, received as a result of interaction between the organism and environment (natural, socio-cultural). Interaction has the historical character, at different levels of organisation definite "structural correlations" (Humberto Maturana) and communications (Jurgen Habermas, Nikolas Luman) appear.

Let us characterize the cognitive apparatus of the postnonclassical science by comparing it with the understanding of cognition in the evolutional 
epistemology. The cognition subject in the evolutional epistemology is much more active than the subject in representative models of cognition, since it is entirely constructed during its development. It appears not only as an evolution product, but as an active participant of the evolutional process. In the evolutional-synergetic paradigm the subject-object dualism fades away, as it was highlighted by Erich Janch and Joseph Prigozhin. Humberto Maturana and Francisco Varela describe the cognition mechanism as a recursive process, where subject and object mutually construct each other. Adherents of the epistemological constructivism describe the cognition in evolutional epistemology as follows "The object can not be discovered, like America was discovered by Columbus, for example. The object is discovered by constructing, in other words, it can be understood only by a consistent approach to it with the help of epistemic structures (categories, notions, cognitive schemes), which are constructed by the subject itself during its interaction with the environment" [9].

The evolutional epistemology became a cognitive tool for many representatives of the historical school of postpositivism, especially for Karl Popper. This position enabled the adherents of the evolutional epistemology to build the argumentation against the epistemological relativism, to foster the objectivity as the highest value of the scientific knowledge. In the constructivist understanding of knowledge the traditional cognitive scheme "subject - object - mental representation knowledge" is a function of linguistic conventions approved in the cultural traditions and standards of the scientific discourse. However, this is only one side of the medal; the reverse side is revealed in the evolutional epistemology and on the basis of the ontology build on the ideas of the global evolutionism and consistency. From this angle, the communicative level of interaction is understood not as a fundamental one, but as evolutionally stipulated.

\section{Results}

The forms of constructivism are quite diversified: radical constructivism, social constructivism, instrumental constructivism, epistemological constructivism and evolutional constructivism. Thus, the processes of comprehension, interpretation, storage and reproduction of information appeared in the centre of attention of social constructivism. Linguistic communication serves as means and method of the symbolical exchange, in process of such communication relatively stable forms of world understanding appear. Here cognition is not an individual property anymore, but it is a product of society members' activity. The representative nature of knowledge is denied, and the social-communicative nature of knowledge is strengthened, which is revealed not only in a humanitarian knowledge, but in natural science as well. The truth discontinues being an analogue of the empirical authenticity and becomes a means of strengthening of social positions. Language and discourse come in the avant-garde of the scientific interests. The social constructivism in its turn can have radical and moderate forms. Social constructivism of Serge Moscovici serves as an example. Unlike the radical constructionism it admits the relative autonomy of social reality and its "empire" over individual, but at the same time it approaches studying those processes, in virtue of which the psychological phenomena produce this reality, remaining its products. The return to knowledge representation happens, but the representation here serves as expression of both subjective and objective worlds, being the product of its relationships. Thereby, the cognitive and communicative aspects of representation are integral parts of each other. Authors offer a model of the evolutional constructivism [10]. In the context of evolutional constructivism the subject constructs an object in accordance with those processes which provide the existence of the subject itself.

In various forms of constructivism the cognition is characterized not as reflection, not as representation or interpretation, but as a cyclic self-referent process of interaction between a subject, an object and communicative environment. The bright metaphor of constructivist interpretation of cognition was offered by Heinz von Foerster - "the process of cognition is a dance of man and the world" [9]. Constructivism is an adequate epistemological scheme of explanation of evolving existence, evolutional processes; cognition here takes the character of sense-production. Thus, the sense does not belong to existence, as Heidegger thought, or to a subject as Kant supposed. It is formed in interspace, not in vacuum, but in emergence, in interaction, in synthesis of existence and cognition. Insofar the objects studied by the postnonclassical science are not limited to material ones, but include relationships, interconnections, processes with the humane participation; the constructivist understanding of the cognition is quite adequate here. In particular, in the synergetic paradigm it is self-organisation, nonlinear processes, cooperative and coherent phenomena. In the synergetic paradigm transcendental subject does not exist, as long as the observer is placed inside the self-organising processsystems, it becomes not only the observer, but the actor as well. Synergetics study the interactions, called selforganisation. From the positions of process ontology we cannot look at reality as a spectator - sidewise, it is necessary to participate and simultaneously to change itself and the reality.

The change in reality image leads to changes in the cognitive regard, the humanization and subjectivity of knowledge (human dimension of the objects of postnonclassical science). However, it does not imply de-ontologisation of reality, but it indicates the formation of new ontology. Objectively the real explanation and description relating to the "human dimension" objects not only admits, but assumes the inclusion of axiological factors to the structure of explicative sentences. Cognition of this type of objects cannot be ethically loaded, it includes the value parameters. At present the understanding of the new type of objectivity takes place, of the more complete objectivity, which includes the subjective dimension, but not denoting subjectivism. "In the basis of the more complete objectivity, which 
includes the science as an activity together with its result, the following formula should be used: Objective $=$ Objectal + Subjective" [11].

Epistemological practice of "human-dimension" objects cognition cannot use the subject-object scheme, in which the subject takes the position of the external observer. The ontology of conscience as an eye placed in front of the world corresponds to this scheme. Moreover, "human-dimension" objects are such complex systems, which are self-organising, their "behaviour" is spontaneous, using the anthropomorphous terms. Understanding of the reality like a process-system, with characteristics, like complexity, spontaneity, nonlinearity and self-development, forms the ontology, where the basic parameters of existence are rethought. Reality is interpreted as a process-system with nonlinear dynamics. Evolution is coevolution, combined evolution of the system and environment. On the basis of the abovementioned we can draw a conclusion that cognitive practice of the evolutional epistemology, where the cognition is understood like a natural-historic process, and knowledge - as an efficient action in the studied area, enable us to rationalize the possibility of conservation of the objectivist attitude of science in cognition of complex, self-developing, "humandimension" systems.

\section{References}

1. V.A. Lektorski, V.S. Styopin, The Ques. of Phil., 10, (2006)

2. D.T. Campbell, Evolutional epistemology. The philosophy of Carl Popper (Le Selle (III.): Open court, 1974)

3. K. Lorenz, Kant's doctrine of the a priori in the light of contemporary biology (General Systems, Yearbook of the Society for General Systems Research, 1962)

4. V.S. Styopin, L.F. Kuznetsova, Scientific worldview in the structure of technogenetics civilization (Moscow, 1994)

5. Modern theories of cognition (Digest of reviews and reports, Moscow, 1992)

6. I.V. Chernikova, Philosophy and history of science (Tomsk, 2001)

7. V.I. Arshinov, V.G. Budanov, Cognitive basis of synergetics (Synergetic paradigm, Moscow, 2002)

8. H. Maturana, F. Varela, The tree of knowledge. Biological basis of human understanding (1984)

9. E.N. Knyazeva, Epistemological constructivism (Philosophy of science, Moscow, 2006)

10. I.V. Chernikova, D.V. Chernikova, Evolutional constructivism: to the issue of "cognition of cognition" (VI International conference on cognitive science: Proceedings, Kaliningrad, 2014)

11. V.I. Moiseev, Ethos of science as a symbol of new objectivity (Philosophy of Science, Moscow, 2005) 